\title{
A Study of Language Transfer in the Process of Second Language Acquisition
}

\author{
Xiaoyan Feng \\ Nanchang Institute of Science \& Technology, Nanchang 330108, China
}

\begin{abstract}
:
Language transfer is one of the important factors in second language acquisition. Based on the language transfer theories the article analyses the language factors which affect language transfer in the process of second language acquisition from the perspective of phonetics pragmatics and syntax in the method of comparative analysis, which can help teachers stimulate their language teaching.

Keywords: Second Language Acquisition; Language Transfer; Mother Language; Target Language
\end{abstract}

\section{Introduction}

The term "transfer" refers to the process of automatic, uncontrolled and subconscious use of past learned behavior the attempt to produce new response. Generally speaking, transfer refers to the effect that mother tongue of old language knowledge has on target language or on the new language knowledge. This effect can be positive or negative, so the transfer can be classified as positive transfer of negative transfer. This positive or negative effect may occur in the process of second language learning so as to have the concept of language transfer. Language transfer is a phenomenon in the process of second language learning, learners of the mother language knowledge, such as pronunciation, semantics, structure and other rules of the new language knowledge of the phenomenon of learning. Language transfer refers to inter-language transfer, that is, the transfer between different languages, such as the mother tongue and the target language, but also refers to intro-language transfer, such as the transfer between vocabulary, structure and the skills of writing and reading. Positive transfer is the process of in which mother tongue has a positive effect on English 
learning. That he influence of the language rules of mother tongue is incompatible on target language is negative transfer. Language transfer can be used to explain the interact among factors in the process of second language learning and influence the acquisition and use of language, and help learners to learn the correct language learning strategies.

\section{The Theories of Language Transfer}

Language transfer is an important topic in the field of second language acquisition research. In the 1950s, Robert Lado first proposed a comparative analysis hypothesis in his linguistic book Cross-Cultural Language. This hypothesis is based on behaviorism and structuralism linguistics, which concluded that the negative influence of mother tongue in second language learning is greater than the positive effect. The greater the difference between mother tongue and target language, the greater the difficulty of second language learning, vice versa. Learners can easily grasp those language points in the target language which are close to or similar to the mother tongue. In addition, Ellis(1999) also believes that the difficulty of second language acquisition and the target language is relevant to the difference between the mother tongue. The greater the difference between the mother tongue and the target language, the more obstacles to the learning of the second language, leading to the emergence of errors in the learning process. However, in practice, this learning disability will be different due to the difference of individual cognitive level. For example, when mother tongue and target language are from the same language and have similar language rules, learners tend to be confused. At the end of the $60 \mathrm{~s}$, Chomsky put forward the universal grammar theory that the human brain has inherent universal grammar, specifically divided into the core grammar and the surrounding grammar, core grammar is common to all languages grammar, is unmarked, the surrounding grammar is specified to different languages, is marked. The ability of language acquisition is innate. The creative construction theory holds that the second language learning process is influenced by the universal grammar. The learners who have different mother tongues have the same process and order of learning the second language. Mother tongue has no obvious influence on the process of second language learning. The theory of deep sharing ability hypothesis is that the mother tongue transfer is no longer only exist in the language surface, but an individual subject of psychological cognitive processing. Mother tongue and target language are interdependent, interrelated in a deeper level, and the development of one language skill can promote the learning of another language. The positive effect of mother tongue on the target language is far more than the negative impact. 


\section{Factors of Language Transfer}

Language factors. English and Chinese belong to two different languages. English belongs to the Indo-European Germanic language system. Chinese belongs to the Sino-Tibetan language Chinese. The differences between the two languages in phonetics, vocabulary and syntax are quite different. Therefore, negative transfer is greater than positive transfer for the majority of Chinese learners in the process of learning English.

English is an intonation language, it mainly determine different semantics through voice and intonation. Chinese is a tone language, it mainly determine different semantics through four different tones. The two languages are different in tone, phoneme and phoneme structure. For example, English learners usually use a tone to read the whole English article without the change of tone and stress intensity, which are mostly affected by the negative impact of their mother tongue---Chinese. In view of this, English teachers should not only focus on the input of the tone but the output of it, and what's more, guide students to do more practicing and imitating. In addition, English phonemes and Chinese phonemes are also very different. There are differences between voiceless and voiced phoneme. English has some phonemes which Chinese hasn't. For example, the two phonemes as $[\theta]$ and [ð], learners are difficult to correctly grasp essentials of their pronunciations, especially for adults. Because their pronunciation system is a complete Chinese pronunciation system, and Chinese does not have these two phonemes. Therefore, the age of language learning is one of the very important factors, teachers for school-age children should allow them to familiar with a variety of pronunciation rules and try a variety of phonemes. English and Chinese also have a small number of similar phonemes, but it will also affect the correct pronunciation of English learners.For example, phoneme [aI] in English is similar to "爱" in Chinese. Although they have the same pronunciation, they have different tones in their respective pronunciation systems. Teachers should not let their students use these similar pronunciation of Chinese characters to mark the pronunciation of English words in order to facilitate students to memorize new words. Teachers must avoid this kind of negative transfer while teaching.

Sapir Wolff hypothesis propose that different language structure will affect the user's habits of thinking, leading them to observe the world in different ways, leading to their different perception of the world. It holds that language is not only a tool for thinking, but strongly affects and constrains human thinking. English and Chinese belong to different language families, and the language users' religious beliefs, values, social lives and historical development are quite different, and their thinking patterns are very different. For example, words of colors in the English and Chinese language have different inner meaning and extended meaning. Red in Chinese means festive, good luck, with a compliment. Red in English often has a derogatory meaning, and means go into the red, be in the red. Green in Chinese is a symbol of nature, while green in English refers to no experience, immaturity and jealousy, such as "green hand, green eyes". Dragon in China symbolizes power, the royal family, but in the mode of 
Westerners' thinking, "Dragon" is a symbol of evil, and will bring disaster to mankind. Therefore, teachers should teach students cultural background knowledge, so that students can correctly understand the different connotation meaning and denotation meaning of words in different languages.

In the process of foreign language learning, the learners because they are not familiar with grammatical rules of target language, they often apply the syntax rules of their mother tongue. However, English and Chinese languages have different syntactic rules, which lead to the negative transfer of the syntactic level. For example, the English and Chinese declarative sentences are the normal word order as SVO, which caused by little negative transfer. But the use of attributive, adverbial and other modified components in a sentence vary greatly, so there are more negative transfer. For example, The sentence "You are going to the school?" should be changed into "Are you going to the school?" The sentence "You have how many books." should be changed into "How many books do you have?"

\section{Inspiration of Positive Transfer of Mother Tongue in Teaching}

Mother tongue has positive and negative effects on foreign language learning for foreign language learners. This dual role will not change because of human will, and it is a contradiction that foreign language teaching theory and practice need to resolve.

In the initial stage of foreign language teaching, it is helpful to make a comparative analysis of the linguistic systems of mother tongue and target language, which is helpful to determine the key points and difficulties in teaching. Teachers can consciously compare students' mother tongue and the target language to find out the differences or similarities between them, so as to determine the key and difficult points based on the characteristics of the students in the initial stage of their foreign language learning.

Attach importance to the contrastive analysis of cultural differences between mother tongue and target language. It is very important to analyze the cultural backgrounds of mother tongue and target language in foreign language teaching because many mistakes in intercultural communication are caused by the lack of awareness of cultural differences between mother tongue and target language. For example, while treating other people's praise, British and American think that quality and quantity should be firstly considered rather than modesty. Chinese often say "惭愧" "哪里" in order to show their modesty whereas Westerners always answer " Thank you ". Teachers should seize every opportunity to introduce students westerners ways of thinking, language expressions, customs and historical background, so that students may know the importance to study cultural background knowledge of English and American .

Appropriate use of Chinese in classroom teaching can achieve a multiplier effect of teaching. While teaching some abstract concepts of vocabulary or grammar, if it cannot be easily explained, teachers can use some appropriate 
mother tongue to explain so that students can understand easily.

The use of mother tongue in classroom teaching should not be too much. Because the purpose of foreign language teaching is to cultivate students' ability to use the language, if there is too much use of mother tongue in the classroom teaching, the chance to contact the target language of students in a limited time will be reduced accordingly. It is not conducive to achieve the purpose of foreign language teaching.

\section{Conclusion}

In conclusion, the transfer of mother tongue to target language inevitably exists in the process of second language acquisition, which has both positive and negative effects. In the process of teaching students English whose mother tongue are Chinese, teachers should understand and recognize the negative transfer phenomenon of Chinese in English teaching, which will help teachers apply positive transfer. Teachers should try to eliminate or reduce the negative impact of negative transfer, so that students can properly understand various English language phenomenon so as to cultivate good learning habits. At the same time, while teaching, teachers should properly guide students so as to promote positive transfer and avoid negative transfer, to ensure the effectiveness of language acquisition.

\section{Acknowledgment}

This research was financially supported by the Jiangxi Province Education Reform Foundation.

Project Name:Practice and Application of VESL Teaching Mode in Applied Technological Undergraduate College

Project Number: JXJG-15-27-5

\section{References}

[1] Lado, R. Linguistic Across Culture Applied Linguistics for Language Teachers. Annarbor, Michigan University of Michigan, 1975.

[2] Faerch, C.\& Kasper, G. Perspectives on Language Transfer. Applied Linguistics, 1987,(8).

[3] Odlin, T. Language Transfer[M]. Cambridge: Cambridge University Press, 1989.

[4] Ellis, R. The Study of Second Language Acquisition[M]. Shanghai: Shanghai Foreign Language Education Press, 1999.

[5] Sharwood Smith and Kellerman. Cross-linguistics Influence in Second Language Acquisition[M]. Oxford: Pergamon, 1986. 